\title{
Impactos que o Treinamento ocasiona no Setor de Produção: Estudo De Caso em uma Empresa de Calçados de Juazeiro do Norte - CE
}

\author{
Wellisson Maxsuel Araújo Andrade ${ }^{1}$; José Leandro de Almeida Neto ${ }^{2}$
}

\begin{abstract}
Resumo: O presente artigo é um estudo de como as ações do treinamento proporcionam melhorias no setor de produção, corrigindo falhas que possam contribuir significativamente para o aumento da qualidade dos produtos fabricados, o desempenho dos funcionários e a competitividade da empresa. O objetivo deste trabalho é apresentar as transformações que o treinamento proporciona para a empresa bem como a sua importância estratégica para melhorar os processos organizacionais, destacando a sua contribuição para o setor produtivo das empresas. O estudo foi realizado em uma empresa de calçados da cidade de Juazeiro do Norte - CE. Como metodologia, realizou-se pesquisa bibliográfica, entrevista estruturada com o Gestor de Recursos Humanos e aplicação de questionário fechado com os funcionários da organização. Foi observado que o treinamento, quando aplicado corretamente, consegue corrigir falhas, torna a produção mais eficaz, qualifica colaboradores, proporcionando resultados extremamente positivos para a organização.
\end{abstract}

Palavras-chave: Treinamento. Produção. Funcionários. Competitividade. Desempenho.

\section{Impacts that training brings about the Production Sector: Case Study on a shoes company in Juazeiro do Norte - CE}

\begin{abstract}
This Article is a study of how the training actions provide improvements in the production sector, correcting flaws that can significantly contribute to increasing the quality of manufactured products, employee performance and competitiveness from the company. The objective of this study is present transformations that the training provides for the company as well as its strategic importance to improve its processes, high lighting its importance and its role in the company's production sector. The study was conducted in a shoe company in the city of Juazeiro do Norte- CE. The methodology, it was held bibliographic research, structured interview with the Manager of Human Resources and application closed questionnaire with the organization's staff. It was noticed that the training, when applied correctly, can fix flaws, makes more efficient production, qualified employees, providing results extremely positive for the organization.
\end{abstract}

Keywords: Training. Production. Employees. Competitiveness. Performance.

\section{Introdução}

As dificuldades e limitações no processo produtivo da empresa impedem de ganhar mais participação no mercado. A mão de obra tem participação direta no processo produtivo da empresa, sendo necessária uma qualificação constante dos funcionários para superar possíveis dificuldades que impedem a empresa de crescer, reduzir os seus custos, bem como falhas no seu processo produtivo para não provocar atrasos na entrega dos produtos, sempre oferecendo qualidade aos seus clientes.

\footnotetext{
${ }^{1}$ Graduando do curso de Administração do Centro Universitário Doutor Leão Sampaio. E-mail: wellissonmaxsuel@ gmail.com.;

${ }^{2}$ Professor do curso de Administração do Centro Universitário Doutor Leão Sampaio. Mestrando em Desenvolvimento Regional Sustentável da UFCA - Universidade Federal do Cariri.E-mail: leandro@leaosampaio.edu.br
} 
A falta do treinamento na empresa pode contribuir para dificuldades de superar erros de fabricação, bem como a forma errônea de utilização das máquinas industriais por parte de funcionários, o que acaba limitando a logística da empresa frente a sua concorrência no ramo de calçados na região do Cariri.

$\mathrm{O}$ treinamento representa a segurança que funcionários adquirem, em um certo período de estudo, para atuarem nos setores o qual foram designados a trabalhar. Um profissional capacitado para desempenhar as suas funções tem menos risco de ter um fraco desempenho, pois o mesmo está ciente de que as técnicas aprendidas antes da prática impactam positivamente em sua performance. O treinamento é eficaz quando aplicado continuamente, pois novas tecnologias estão sempre surgindo e o profissional bem preparado para essas mudanças pode adquirir mais segurança nas atividades que vai desempenhar, corrigindo falhas, o que pode impactar positivamente na empresa.

Diante do desempenho fraco de alguns colaboradores e a ocorrência de falhas no processo produtivo, questiona-se qual a importância e quais os impactos que o treinamento provoca nos funcionários e na empresa?

$\mathrm{O}$ presente estudo tem como objetivo geral analisar os impactos que o treinamento proporciona para a empresa bem como a sua importância estratégica para melhorar os seus processos, destacando a sua contribuição para o setor de produtivo das empresas. Os objetivos específicos são definir o treinamento, apresentar as vantagens do treinamento para a empresa e o colaborador e identificar indicadores de qualidade no setor produtivo, buscando constatar a influência do treinamento no desempenho dos mesmos.

O trabalho se preocupa em contribuir para o entendimento sobre o treinamento e os impactos que proporciona, auxiliando os empresários a entenderem o processo produtivo de das empresas e corrigir falhas que possam contribuir significativamente para um aumento da qualidade dos produtos fabricados, o desempenho dos funcionários e competitividade da empresa.

Além disso, vale ressaltar a importância econômica que as empresas de calçados oferecem para a cidade de Juazeiro do Norte - CE, sendo necessário estudá-las e caso problemas sejam identificados no setor produtivo, pesquisas acadêmicas possam auxiliar em decisões que melhorem o desempenho produtivo a partir de estudos científicos, sendo necessário que a teoria seja aplicada na prática cotidiana de empresas que possam estar com dificuldades em produzir os seus produtos bem como melhorar o rendimento dos funcionários que trabalham em empresas de calçados.

Para a realização desta pesquisa científica inicialmente utilizou-se de recursos bibliográficos, onde foram coletados informações sobre o treinamento e as formas de aplicação na opinião de diversos autores que estudam a área de Recursos Humanos. A pesquisa caracterizou-se com qualiquantitativa, onde foram colhidas informações com o gestor responsável pela aplicação do treinamento na empresa e aplicação de questionário fechado utilizando escala de Likert com funcionários da 
organização, para saber qual era a percepção dos mesmos sobre a aplicação dos treinamentos e quais transformações eram observadas após os períodos dos treinamentos. Verifica-se que o treinamento quando aplicado corretamente pode transformar empresas, por ser uma atividade que auxilia a organização em um melhoramento contínuo.

\section{Conceito de Treinamento}

$\mathrm{O}$ treinamento é fundamental para as empresas renovarem o conhecimento tornando os processos mais eficientes procurando reduzir os seus custos. Os profissionais que atuam na empresa constituem o grupo importante para o bom funcionamento da organização, desde que estejam sempre atualizados para desempenharem as tarefas delegadas na empresa. O treinamento é indispensável para a organização que quer ter um destaque frente à concorrência, pois ensina novos métodos eficazes, corrigindo falhas, aperfeiçoando os produtos e serviços oferecidos pelas empresas, tornando a qualidade necessária para os seus clientes.

Segundo Marras (2011, p. 145) "Treinamento é um processo de assimilação cultural a curto prazo, que objetiva repassar ou reciclar conhecimento, habilidades ou atitudes relacionadas diretamente à execução de tarefas ou à sua otimização no trabalho". É nesta fase que ocorrem as transformações necessárias para um bom desempenho das pessoas envolvidas com a produção através do estudo de novas técnicas ou o aprimoramento de conhecimentos já adquiridos. França (2012, p. 88) complementa dizendo que "[...] treinamento é um processo sistemático para promover a aquisição de habilidades, regras, conceitos e atitudes que busquem a melhoria da adequação entre as características dos empregados e as exigências dos papéis funcionais [...]".

No treinamento é possível simular situações relacionadas com o cotidiano profissional dos colaboradores, permitindo a prática daquilo que está sendo estudado, sendo que neste período podem acontecer erros que denunciam as fragilidades que podem ser corrigidas por o treinamento ser um processo de aprendizagem. Na opinião de Milioni (2001, p. 10), o treinamento "é a ação sistematizada de educação para a capacitação, o aperfeiçoamento e o desenvolvimento do indivíduo". O treinamento tem a capacidade de modificar atitudes por promover ações mais assertivas. Chiavenato (2008, p. 367) completa dizendo que "O treinamento é uma maneira eficaz de delegar valor às pessoas, à organização e aos clientes. Ele enriquece o patrimônio humano das organizações". O conteúdo do treinamento permite a qualificação profissional de funcionários que por sua vez beneficia a organização por ter em seu quadro produtivo profissionais capacitados, tendo como consequência, a oferta de produtos e serviços com qualidade para clientes. 
Id on Line Revista Multidisciplinar e de Psicologia

Id on Line Multidisciplinary and Psychology Journal

\section{Importância do treinamento}

O treinamento possui importância por proporcionar a competência profissional necessária para os colaboradores desempenharem bem as suas funções dentro da organização e ainda por promover valor econômico para a empresa e de valor social para o empregado. Segundo Zarifan (2008, p. 66) "[...] a competência profissional é uma combinação de conhecimentos, de saber fazer, de experiências e comportamentos que se exerce em um contexto preciso [...]".

Lacombe (2005) afirma que empresas passam por dificuldades porque muitas vezes seus métodos para a produção estão desatualizados, ocasionando perdas no seu setor produtivo como a diminuição das receitas por altos custos estarem associados à produção, as falhas nos processos provocadas por funcionários que muitas vezes não estão preparados para esses processos, o que acaba sobrecarregando-os com um método de trabalho ultrapassado para o atendimento da sua demanda. $\mathrm{O}$ treinamento é um ciclo de aprendizagem que contribui para a capacitação de funcionários para desempenharem suas funções dentro das organizações. Na concepção de Gil (2001, p. 121) treinamento é "[...] o meio para adequar cada pessoa a seu cargo, com vista no alcance dos objetivos da organização [...]". Lacombe (2005, p. 311) ainda completa dizendo que “[...] Treinamento não é algo que se faça uma vez para novos empregados: é usado continuamente nas organizações bem administradas. Cada vez que você mostra a uma pessoa como ela deve fazer o trabalho, você a está treinando [...]". O treinamento é um processo que sempre estará renovando os padrões, os métodos e melhorando o sistema para melhor, beneficiando a organização.

Existe uma diferença entre treinamento e desenvolvimento das pessoas. Entende-se que o treinamento tem a finalidade de melhorar as habilidades do profissional no desempenho de suas funções. Segundo Chiavenato $(2008$, p. 367) "O treinamento é orientado para o presente [...] e o desenvolvimento de pessoas para cargos a serem ocupados futuramente [...]".

Sabe-se que a principal estratégia para a realização do treinamento é a estrutura preparada e desenvolvida pela organização. Pois este processo deve estar equilibrado em uma linha de realizações. Segundo Gil (2001), o treinamento é um sistema que abrange vários subsistemas os quais são compostos pelo diagnóstico, prescrição, execução e avaliação. Ressalta ainda que a visão sistêmica do programa de treinamento possui a vantagem de incorporar contribuições científicas ao plano de treinamento.

Já de acordo com Chiavenato (2008) o treinamento é um processo cíclico e contínuo composto de quatro etapas: O diagnóstico, que é quando existe o levantamento das necessidades ou carências de treinamento a serem atendidas ou satisfeitas. O desenho, que é a elaboração do projeto ou programa de treinamento para atender às necessidades diagnosticadas. A implementação, que é a execução e condução do programa de treinamento e por último, a avaliação, que consiste na verificação dos resultados obtidos com o treinamento. 
As organizações estão inseridas em um mundo dinâmico, onde constantemente mudanças acontecem, estabelecendo um cenário competitivo para a produção, provocando nas empresas uma necessidade constante de atualização, acompanhando essas transformações. Segundo Zarifan (2008, p. 94) "Uma das características fortes do período atual é que nenhuma organização pode ser considerada definitivamente estabelecida e eficaz: existe uma transformação contínua entre competências e desempenhos $[\ldots]$ ".

\section{Objetivos e necessidades do treinamento}

Empresas possuem metas que pretendem alcançar. O treinamento é um importante aliado por auxiliar na concretização de objetivos depois da análise de necessidades organizacionais.

Marras define os objetivos do treinamento sendo eles:

Formação Profissional: que tem como base, elevar o conhecimento do profissional à sua profissão, para elevar o seu desempenho nas suas atividades. Especialização: oferece a oportunidade do empregado de treinamentos voltados a uma área de conhecimento específico. Reciclagem: é a oportunidade de se atualizar dos conhecimentos já aprendidos na sua rotina de serviço (MARRAS, 2011, p. 148).

Vargas e Abbad (2006) afirmam que o treinamento de pessoas tem o objetivo de aplicar uma educação formal, existindo a necessidade das empresas estarem sempre investindo em ações para atualizar seus funcionários por novas tecnologias estarem sempre surgindo. Sallorenzo (2000) explica que o treinamento proporciona um processo de aprendizagem e propicia o amadurecimento de indivíduos de forma ampla, algumas vezes não sendo restrito apenas para um posto de trabalho.

Para desempenharem suas atividades com qualidade, é necessário que empregados tenham um conhecimento profissional antes de estar inserido no processo produtivo para desenvolverem melhor suas atividades, existindo assim a necessidade de renovar esses conhecimentos adquiridos para aperfeiçoar ainda mais a produtividade, pois o treinamento consiste em um processo cíclico onde deficiências sempre podem ser corrigidas periodicamente nas organizações que apresentam alguma restrição no seu processo de fabricação de seus produtos. Segundo Zarifan (2008) o objetivo não é obrigar um colaborador a ser competente, o que a empresa pode fazer é requerer competências, criando condições favoráveis para o desenvolvimento profissional e ao mesmo tempo validá-las.

Marras (2011) comenta que o levantamento das necessidades responde basicamente a duas perguntas iniciais, que são: Quem deve ser treinado? E o que deve ser aprendido? Como resposta, são os profissionais que estão diretamente ligados ao setor produtivo, que todos os dias no seu trabalho estão operando máquinas e outros ligados ao desenvolvimento de planos estratégicos, pois são eles 
que elaboram os orçamentos voltados ao melhor funcionamento das atividades logísticas da empresa. Como aprendizado, estes profissionais adquirem a capacidade de operar melhor as máquinas e aplicar novos métodos para obter resultados satisfatórios e jamais vistos na empresa anteriormente.

Segundo Lacerda e Abbad (2003), o processo de treinamento deve ser entendido como um conjunto de atividades interdependentes ou um subsistema, onde são levantadas as necessidades da empresa para a aplicação do treinamento, que deve ser planejado, permitindo assim uma orientação para a execução e avaliação do treinamento, possibilitando um feedback com os ajustes necessários para os outros componentes do sistema, tornando o processo de renovação de conhecimento mais eficiente dentro da empresa.

É necessário sempre disponibilizar para esses funcionários uma reciclagem de conhecimento, pois novos métodos e operações estão em contínuo aperfeiçoamento no meio científico, podendo ser aplicado na organização através do treinamento, existindo assim uma necessidade de atualizar conhecimento na organização. Chiavenato (2002, p. 505) comenta que: "O levantamento de necessidade de treinamento deve fornecer informações para que possa traçar a programação de treinamento". Lerner (2002) completa dizendo que a necessidade do treinamento está ligada as qualidades profissionais, refletindo os padrões de conduta e habilidades necessárias para os colaboradores desempenharem com êxito a ocupação dentro da organização.

\section{Planejar o treinamento}

Para aplicar o treinamento, antes de tudo deve existir um planejamento, para que a execução seja perfeita e que na avaliação do treinamento seja possível identificar melhorias provocadas por esta ação que é capacitar as pessoas para melhor atuarem na organização. Segundo Lerner (2002) o treinamento deve estar alinhado com os valores organizacionais e estratégicos da empresa para que a sua prática seja eficaz quanto a tempo e dinheiro.

Marras (2011) diz que o planejamento do treinamento é o elo entre as políticas, diretrizes e ações formais e informais que regem as relações da empresa. Na concepção de Santos (2001), é o estabelecimento dos objetivos da organização, especificando o modo pelo qual esses objetivos serão alcançados. Desenvolve-se a partir de uma visualização do futuro de forma que seja possível traçar estratégias para atingir as metas especificadas. É determinada como primeira das funções por ser a base para o direcionamento das demais funções organizacionais. Milioni (2001) completa dizendo que o planejamento consiste em buscar informações que levem a uma conclusão sobre o alcance dos objetivos propostos para um acontecimento, no caso, sendo melhorar a situação dos funcionários dentro da organização através do treinamento. 


\section{Tipos de treinamento}

Existem várias formas de treinamento, seja quanto à forma de aplicação, a metodologia, o público-alvo e o local da capacitação. Para Lacombe (2005) os tipos de treinamento se diferem quanto à forma de execução, podendo ser no trabalho, formal interno, formal externo ou à distância e quanto ao público-alvo, como o treinamento no trabalho e o treinamento formal interno, sendo direcionado para colaboradores da empresa, existindo ainda o treinamento formal externo que é um tipo de treinamento aberto ao público. Existe ainda a modalidade de treinamento à distância, que dependendo do conteúdo, pode ser aplicado tanto para funcionários como pode estar aberto à sociedade, com a finalidade de capacitação pessoal através de videoconferências, de intranet e da Internet. Chiavenato (2008, p. 376) comenta que "[...] o treinamento pode ser entregue de várias maneiras: no trabalho, na classe, pelo telefone, através do computador ou via satélite. A mídia é muito variada [...]".

Os tipos de treinamento se diferem quanto a sua metodologia e finalidade. Para Snell (2009) o treinamento no local de trabalho possui a vantagem de colocar o colaborador em condições práticas da rotina, com a finalidade de melhorar as ações produtivas e também melhorar as relações no ambiente de trabalho. Existe também o treinamento profissionalizante, sendo que nesta modalidade, o profissional recebe instruções especializadas, abordando aspectos práticos e teóricos relativos à função. Já o treinamento cooperativo, é direcionado para estudantes do ensino médio e instituições de ensino superior que possuem vínculo com programas para experiências em tempo parcial ou integral, com a finalidade de integrar experiência prática com aulas de educação formal. Programas de estágios é um tipo de treinamento direcionado para estudantes de nível superior e outras organizações com a finalidade de oferecer aos estudantes a prática daquilo que é visto em sala de aula. E-learning, é um treinamento realizado por mídia eletrônica com finalidade de treinamento à distância e o método de simulação, que dá ênfase ao treinamento com uso de equipamentos, simulando a realidade com finalidade de reduzir custos e maximizar a segurança.

Tabela 01: Tipos de Treinamento

\begin{tabular}{|l|l|l|}
\hline \multicolumn{1}{|c|}{ Quanto à forma de execução } & \multicolumn{1}{|c|}{$\begin{array}{c}\text { Quanto a sua metodologia e } \\
\text { finalidade }\end{array}$} & \multicolumn{1}{|c|}{ Quanto ao público alvo } \\
\hline No trabalho & Profissionalizante & Colaboradores da empresa \\
\hline Formal interno & Cooperativo & $\begin{array}{l}\text { Aberto ao público/Outras } \\
\text { empresas }\end{array}$ \\
\hline Formal externo & Programas de estágios & $\begin{array}{l}\text { Funcionários, estudantes e } \\
\text { sociedade }\end{array}$ \\
\hline Á distância & E-learning & Sociedade \\
\hline
\end{tabular}

Fonte: Adaptado de Lacombe (2005), Chiavenato (2008) e Snell (2009). 
Existem ainda jogos que se enquadram na modalidade de treinamento. Para Kroehnert (2001) a maioria dos jogos possui o objetivo de incentivar o funcionário a competir consigo mesmo, incentivando a buscada melhor ação para resolução de problemas. Dramatizações também são utilizadas em treinamentos para descobrir como os participantes reagem a certas situações, permitindo colocar em prática tudo aquilo que foi aprendido. Mesmo errando os participantes aprendem. É possível aplicar estudos de casos em processos de treinamentos, onde um caso é extraído do ambiente de trabalho dos participantes para ser estudado por um grupo ou um indivíduo, procurando chegar a uma conclusão para o problema, tal resposta pode ser comparada ao que na verdade aconteceu e quais foram as consequências.

\title{
Executando e Avaliando o Treinamento
}

Para Marras (2011) a execução é a aplicação prática daquilo que foi planejado e programado para suprir as necessidades de aprendizagem observadas na organização. Chiavenato faz uma abordagem de que a execução do treinamento é composta em dois termos, sendo eles "instrutor $\mathrm{x}$ aprendiz" com as seguintes definições:

\begin{abstract}
Aprendizes são as pessoas situadas em qualquer nível hierárquico da empresa e que necessitam aprender ou melhorar seus conhecimentos sobre alguma atividade ou trabalho. Instrutores são as pessoas situadas em qualquer nível hierárquico da empresa, experientes ou especializados em determinada atividade ou trabalho e que transmitem seus conhecimentos aos aprendizes (CHIAVENATO, 2002, p.514)
\end{abstract}

A execução do treinamento requer cuidados para empresa e empregados. É necessário que aconteça em um cenário onde estas ações sigam um plano de desenvolvimento, onde já foram acertadas as limitações entre empresa e empregados, para que a empresa não desrespeite a identidade de seus colaboradores, assegurando assim a efetividade das ações de desenvolvimento. Segundo Dutra (2001) as ações de desenvolvimento profissional dentro da empresa requer adequação das políticas de treinamento respeitando a individualidade e singularidade dos colaboradores.

Marras (2011) comenta que a avaliação de treinamento tem por finalidade conferir os resultados conseguidos comparando com aquilo que foi planejado e esperado pela empresa. Chiavenato (2002) completa dizendo que a avaliação de treinamento é a etapa final do processo de treinamento, sendo que, é nesta etapa onde acontece a avaliação dos resultados obtidos.

O programa de treinamento deve ter uma avaliação de sua eficiência para comprovar os impactos causados na organização. Chiavenato faz a seguinte abordagem da avaliação do programa de treinamento: 
Como os programas de treinamento representam um investimento em custo - os custos incluem materiais, tempo do instrutor, perda de produção enquanto os indivíduos estão sendo treinados e por isso estão afastados dos seus cargos -requer um retorno razoável desse investimento. Basicamente, deve-se avaliar se o programa de treinamento atende as necessidades para as quais foi desenhado. Respostas às questões abaixo podem ajudar a determinar a eficácia do programa de treinamento: As rejeições e refugos foram eliminados? As barreiras foram removidas? Os custos por trabalho por unidade diminuíram? As pessoas se tornaram mais produtivas e felizes? A organização alcançou seus objetivos estratégicos e táticos? Se a resposta às questões acima foi positiva, o programa de treinamento foi bem sucedido. Se for negativa, o programa de treinamento não atingiu seus objetivos e o seu esforço foi inválido e sem efeito (CHIAVENATO, 2008, p. 382).

O treinamento quando aplicado e obedecido às etapas para a sua implantação é capaz de aperfeiçoar o nível de produção da empresa, melhorando o seu desempenho no mercado, corrigindo falhas, satisfazendo não só as necessidades organizacionais mas também proporcionando qualidade aos seus clientes. Segundo Gramigna (2007) a avaliação prevê o recebimento de diversos feedbacks daqueles que fazem parte do processo produtivo, para observar acertos e desfrutar melhorias.

\section{A eficiência do treinamento}

Para criar um projeto de treinamento, é necessário ter um diagnóstico da empresa para que quando o treinamento for aplicado obedeça a uma sequência lógica, seguindo objetivos, aplicando um método que atenda e não desperdice a alocação de recursos para só assim conseguir desfrutar de resultados positivos na indústria. Borges-Andrade e Bastos (2002) relatam a ocorrência de avanços significativos na elaboração de medidas para acompanhar as reações e comportamento quando o treinamento é aplicado. Salas e Cannon-Bowers (2001) dizem que o treinamento é eficiente porque é uma ciência, sendo o resultado de uma união de conceitos de várias disciplinas como Administração, Psicologia, Pedagogia e Sociologia que quando aplicado de forma organizada e sistematizada é capaz de modificar o comportamento das pessoas no seu ambiente de trabalho.

Impacto de treinamento no trabalho se refere ao nível de avaliação denominado comportamento no cargo e pode ser entendida como a ocorrência de melhorias significativas da pessoa treinada, como resultado da aplicação no trabalho dos conhecimentos, habilidades e atitudes aprendidos em treinamento. Borges-Andrade e Bastos (2002) afirmam que esses impactos têm sido mensurados pelos pesquisadores, sendo possível obter resultados positivos. Abbad (2000) completa dizendo que a eficiência do treinamento está relacionado com a satisfação dos participantes com o que está sendo transmitido durante os treinamentos, como as informações, o apoio no desenvolvimento, a aplicabilidade, a utilidade e os resultados. 
A eficiência do treinamento está relacionada com as características dos treinandos, que se centraliza na investigação de interações e aptidões e tratamentos, em vez de aplicar diferentes métodos de treinamento, tornou-se importante a verificação das características dos treinandos como habilidades, motivação, atitudes e expectativas ou interações em processo justamente para alinhar o treinamento com o planejamento estratégico da organização, procurando um processo de capacitação que melhor atende as estratégias, pois o que não combina com a visão, missão e valores da empresa não deve sair nem do papel. Meneses (2002) afirma que o relacionamento de características dos treinamentos com sua clientela melhora significativamente quando a organização oferece suporte à transferência de conhecimentos necessários para impactar positivamente as ações no ambiente de trabalho.

Para Borges-Andrade e Freitas (2004), para obter a eficiência do treinamento no trabalho é necessário observar as características individuais, que é o comprometimento no trabalho, motivação para o treinamento e idade. É importante também observar as características do treinamento e de suporte que é aquisição de novas habilidades, sendo necessário analisar antes da execução para que a empresa alcance níveis satisfatórios de eficiência, pois novos conhecimentos apresentam maiores índices de impacto do que os treinamentos que buscam apenas reciclar conhecimentos antigos. É importante aplicar conceitos novos para acompanhar as evoluções do cenário econômico que o meio industrial está inserido.

\section{Metodologia}

Inicialmente foi feita uma pesquisa bibliográfica no período inicial do semestre para obter informações sobre a importância do treinamento nas organizações e o impacto causado na empresa quando o mesmo é aplicado. Segundo Gil (2008) a pesquisa bibliográfica é desenvolvida com material já elaborado, constituído principalmente de livros e artigos científicos.

A pesquisa caracterizou-se como bibliográfica e foi realizada uma pesquisa descritiva com abordagem quali-quantitativa. Para Gil (2008) a pesquisa descritiva possui o objetivo de descrever as características de determinadas populações e fenômenos. Uma de suas peculiaridades está na utilização de técnicas padronizadas de coleta de dados, tais como questionário e a observação sistemática.

O cenário da pesquisa foi uma indústria de calçados da cidade de Juazeiro do Norte - CE. As indústrias de calçados de Juazeiro do Norte - CE possuem grande relevância no cenário econômico nacional se destacando como pólo calçadista do Nordeste há 40 anos. 
Os sujeitos da pesquisa são: o Gestor de Recursos Humanos e trinta funcionários da empresa. A amostra não probabilística foi intencional para o gestor e amostra aleatória simples voluntária sem repetição para os funcionários, partindo do critério de acessibilidade para a realização da pesquisa científica.

A coleta de dados foi feita através de uma entrevista estruturada com o gestor de Recursos Humanos e aplicação de um questionário com perguntas fechadas utilizando a escala de Likert para os colaboradores da empresa, onde foi observado, analisado e registrado o levantamento da aplicação do treinamento na empresa.

A análise dos dados obtidos na entrevista com o gestor de Recursos Humanos e questionário aplicado com os colaboradores passou por uma análise interpretativa. Foi utilizado ainda o programa Excel para a realização dos cálculos dos dados e a inserção dos resultados em gráficos.

O presente estudo está de acordo com a resolução 466/12 do Conselho Nacional de Saúde que normatiza as pesquisas com seres humanos.

\section{Resultados e Discussões}

Inicialmente, o questionário aplicado na empresa buscou encontrar respostas do gestor se existe treinamento na organização. Marras (2011) comenta que o treinamento é importante para as empresas, por ser uma atividade capaz de ensinar novos conhecimentos ou reciclar conhecimentos já adquiridos, melhorar habilidades ou atitudes relacionadas à execução do trabalho. O gestor respondeu que:

Sim, existe treinamento na empresa. Para que a empresa cresça é necessário que aconteça treinamento. É importante que os nossos colaboradores tornem-se cada vez mais capacitados. Todos devem ter o maior domínio possível sobre a área em que atuam, para que assim cometam o menor número de erros, que não venha prejudicar a empresa. Para que isto aconteça, todos passam por uma capacitação. É preciso treinar os funcionários constantemente para obter um crescimento empresarial (GESTOR PESQUISADO, 2016).

Foi perguntado quais as formas de aplicação do treinamento na empresa. Snell (2009) diz que existem várias formas de aplicação dos treinamentos, cabe à organização procurar aplicar aquela capacitação profissional que mais se adéqua com os recursos da empresa. O gestor respondeu que:

O treinamento acontece no ambiente de trabalho. Existem casos em que o colaborador já chega com uma preparação técnica para desempenhar a sua função e o treinamento no ambiente de trabalho da empresa tem o objetivo de familiarizar as pessoas com as atividades da nossa organização (GESTOR PESQUISADO, 2016). 
A pesquisa também procurou saber onde acontecia esta capacitação. O responsável pela gestão de pessoas disse que: "Acontece na própria empresa." Foi perguntado quem realiza os ensinamentos de capacitação do pessoal. O gestor disse que: "Todo o processo de treinamento na empresa, como o planejamento, execução e avaliação está sobre minha responsabilidade.”. E quando acontece? O gestor comentou que: "Os treinamentos são realizados com novos funcionários. Também é realizado periodicamente quando procuramos melhorar a capacidade das pessoas nas tarefas produtivas". O questionário ainda buscou saber se é possível identificar resultados, impactos ou transformações depois da aplicação dos treinamentos. O gestor disse que:

É possível observar mudanças após os treinamentos, como a redução significativa de erros nos produtos fabricados e nas atividades relacionadas à produção, o que consequentemente aumenta a qualidade dos produtos fabricados, reduz custos e aumenta as receitas da empresa. Também é possível perceber, um aumento da produtividade, a produção se torna cada vez mais eficaz. Esses impactos são observados pelo setor da qualidade que acompanha todo o processo produtivo (GESTOR PESQUISADO, 2016).

Foi perguntado se o treinamento possuía único objetivo aumentar a produtividade ou também permitir um desenvolvimento pessoal dos funcionários. O gestor respondeu que: "Temos a preocupação de melhorar o desenvolvimento das pessoas que contribuem para o bem da nossa empresa. O nosso objetivo também com o treinamento é melhorar a nossa produtividade". A pesquisa ainda procurou respostas do gestor para saber qual a influência dos treinamentos para o desempenho do setor produtivo da empresa. $\mathrm{O}$ gestor disse que:

Os treinamentos influenciam muito na melhoria do nosso processo produtivo como a entrega dos produtos cumprindo prazos, cumprindo orçamento, saldo positivo no custo benefício, que é a taxa de retorno, qualidade para o cliente, diferenciação da concorrência, fabricando novos produtos aplicando novas técnicas através dos treinamentos (GESTOR PESQUISADO, 2016).

O questionário buscou saber se existem indicadores de qualidade de produção acompanhados pela empresa. O Gestor de Recursos Humanos respondeu que: "A empresa trabalha com indicadores de qualidade, sendo eles: indicadores de eficiência e eficácia, indicadores de produtividade, indicadores de lucratividade e indicadores de competitividade". O gestor finaliza dizendo que: "O treinamento é realizado a todos os funcionários da empresa. Os resultados são extremamente positivos e que por este motivo vejo com bons olhos investir capital financeiro em treinamento, porque tanto a empresa como os funcionários crescem".

É possível observar os seguintes resultados da aplicação do questionário direcionado aos funcionários da empresa: A maioria dos respondentes é do sexo masculino, que correspondeu a 70\% da pesquisa. Já o público feminino correspondeu a 30\% da pesquisa. 
Com relação à idade dos colaboradores que trabalham na empresa, participantes da pesquisa, $53 \%$ estão entre 26 a 35 anos, representaram a maioria da pesquisa. Até 25 anos, correspondeu a $40 \%$ e $7 \%$ estão entre 36 a 45 anos.

Sobre o tempo de trabalho na empresa, a maioria dos participantes responderam que estão entre 6 e 10 anos, correspondendo a 47\%. Em seguida, 33\% responderam que trabalham na empresa entre 3 e 5 anos e por último, $20 \%$ responderam que trabalham na empresa até 2 anos. Com este resultado, verifica-se que a empresa possui um quadro de funcionários com um certo amadurecimento com relação ao tempo de serviço.

Foi perguntado aos colaboradores se existia treinamento na empresa. Todos os colaboradores responderam que sim, existe treinamento, o que representou 100\%. Este resultado está de acordo com a resposta do gestor, que afirmou na entrevista que existe treinamento na empresa e que existem uma preocupação quanto à capacitação dos funcionários. Conforme Milioni (2001) diz, que o treinamento é um processo de melhoria e adequação dos funcionários. É um ciclo contínuo de capacitação, aperfeiçoamento e desenvolvimento de pessoas e processos organizacionais.

A pesquisa ainda procurou saber qual era a opinião que os funcionários tinham sobre os treinamentos. É possível observar uma grande satisfação com os treinamentos, sendo que o maior percentual considera adequado. Entende-se que existe um respeito quanto à aplicação dos treinamentos na empresa. Isto confirma o que Dutra (2001) diz, que para aplicar o treinamento com perfeição é necessário respeitar as limitações de cada indivíduo, requer adequação, observar singularidades para que não ocorram desrespeitos com as pessoas que colaboram para o crescimento da empresa. O gráfico abaixo ilustra essas respostas.

Gráfico 01: Opinião sobre os treinamentos.

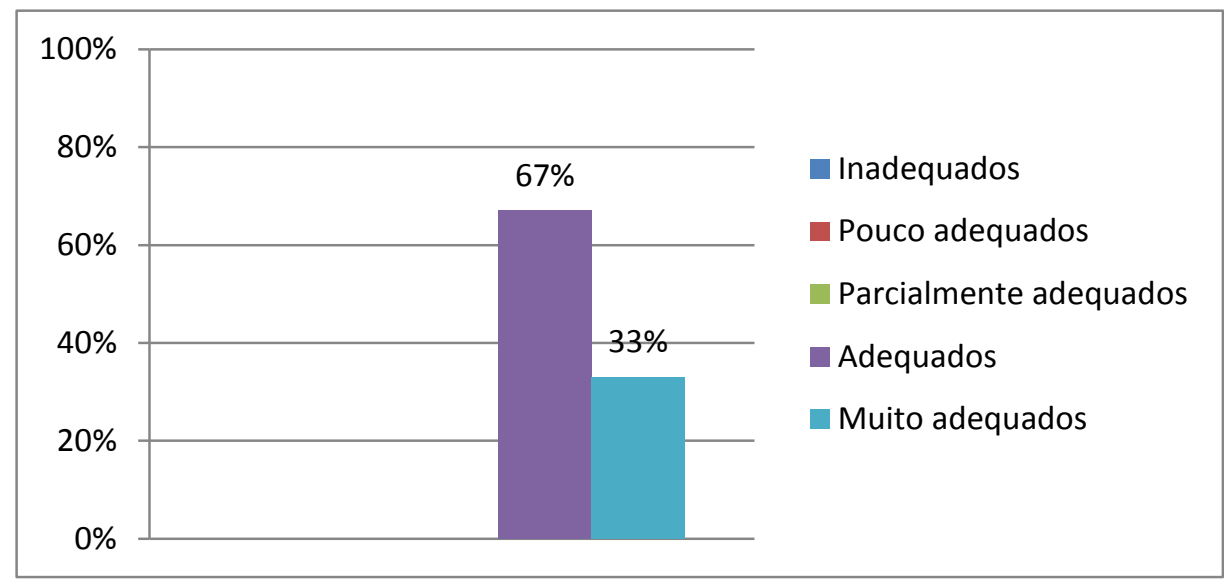

Fonte: Dados da Pesquisa (2016)

Sobre qual era a opinião dos colaboradores com relação às informações passadas no treinamento com relação à prática diária de trabalho, todos os respondentes disseram que as 
Id on Line Revista Multidisciplinar e de Psicologia

Id on Line Multidisciplinary and Psychology Journal

informações melhoram a prática diária de trabalho, sendo que o maior percentual considera adequado. Esse resultado torna o treinamento mais eficiente, pois segundo Borges-Andrade e Freitas (2004) os treinamentos se tornam mais eficientes em seus resultados quando a informação é aprendida com sucesso, principalmente quando se tratam de novos conhecimentos, novas habilidades, o que impacta positivamente o desempenho dos colaboradores, pois estes passam a não só reciclar conhecimentos já adquiridos como também colocar em prática um conhecimento que até então era desconhecido no meio produtivo. O gráfico abaixo ilustra essas respostas.

Gráfico 02: Opinião sobre a informação passada no treinamento com relação à prática diária de trabalho.

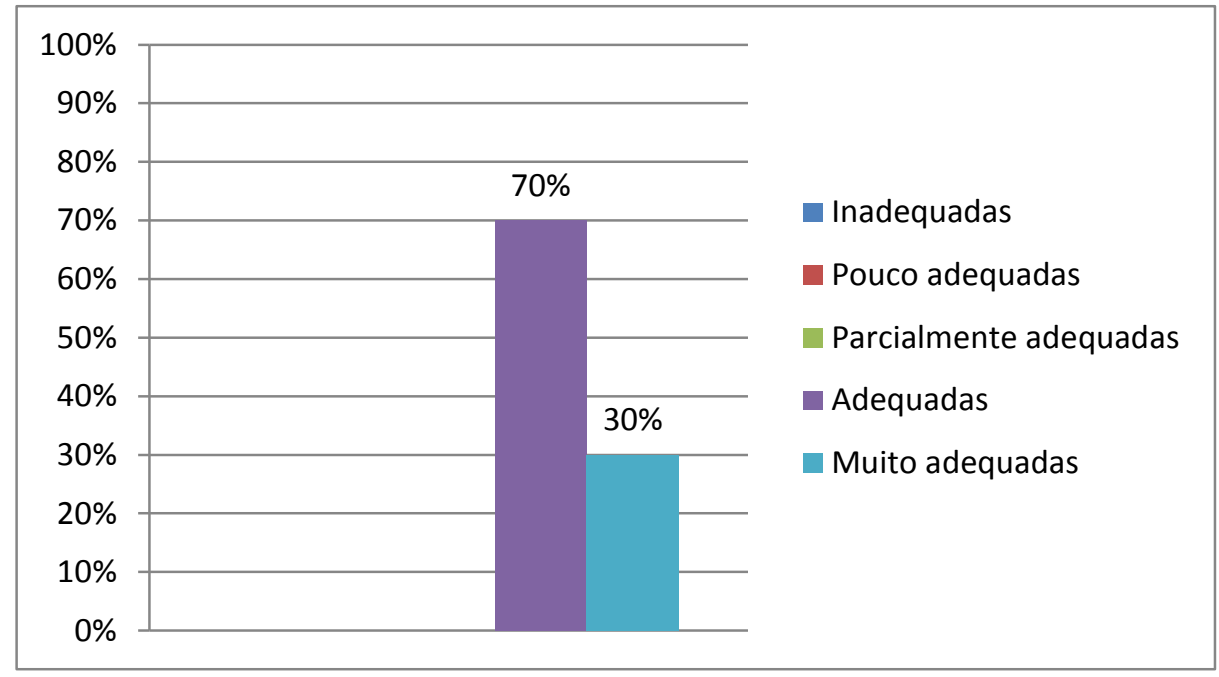

Fonte: Dados da pesquisa (2016)

Procurou-se também saber qual era a opinião dos funcionários sobre a adequação das atividades realizadas nos treinamentos para a melhoria de seu desenvolvimento profissional. Todos os participantes responderam que existe harmonia das atividades com relação ao seu desenvolvimento profissional, sendo que a maioria das pessoas que trabalham na empresa respondeu que existe adequação (57\%), enquanto que o segundo percentual (43\%) consideram que as atividades realizadas nos treinamentos são muito adequadas. Verifica-se que o programa de treinamento da empresa também procura melhorar o desenvolvimento profissional das pessoas da organização, o que está de acordo com as respostas do gestor de pessoas que afirma que a finalidade dos treinamentos tem o objetivo de melhorar as pessoas e também melhorar a produção.

Chiavenato (2008) comenta que quando a empresa aplica o treinamento observando a sua adequação, avaliando as necessidades para aplicar métodos corretivos, faz com que o processo de capacitação profissional se torne uma atividade importante para a organização, por estar delegando valor às pessoas e que tanto a organização quanto os colaboradores se beneficiam das ações de capacitação pessoal. Observe o gráfico abaixo. 
Gráfico 03: Opinião sobre a adequação das atividades realizadas nos treinamentos para melhoria do desenvolvimento profissional.

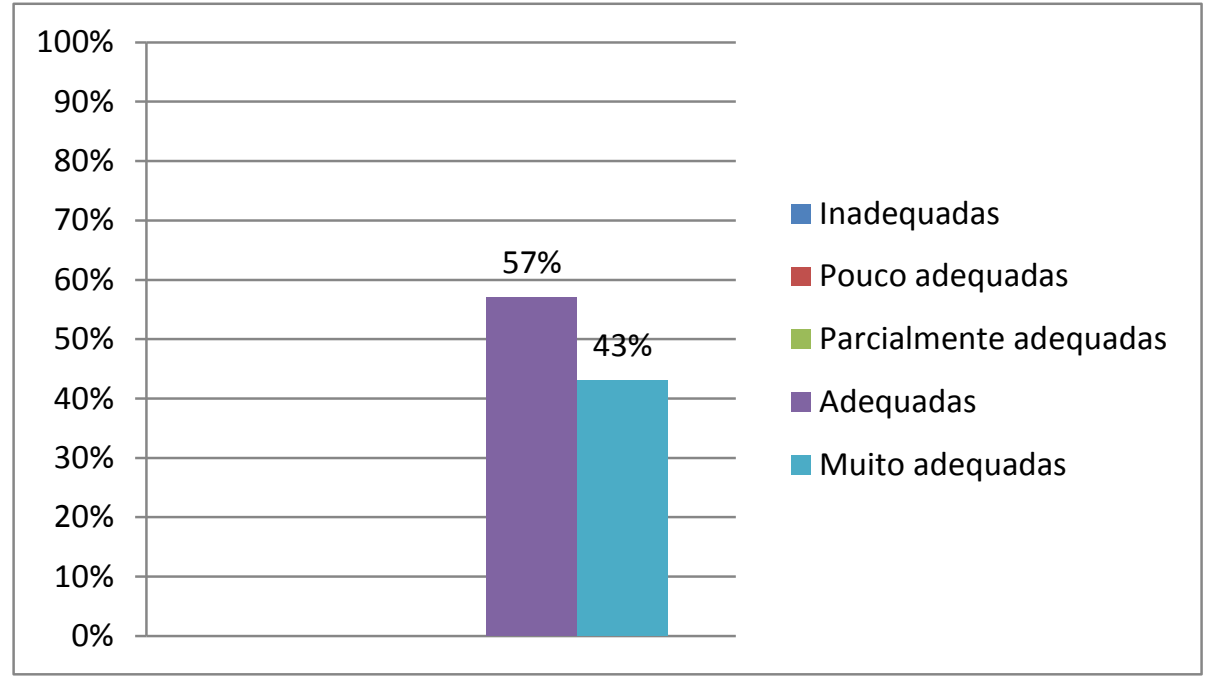

Fonte: Dados da pesquisa (2016)

Os colaboradores ainda foram questionados como eles avaliavam os impactos ou transformações ocorridas depois dos treinamentos. Todos os colaboradores concordam que existem impactos após a aplicação dos treinamentos, sendo que foi possível observar um índice elevado de funcionários que consideram essas transformações muito adequadas (73\%) após os treinamentos, enquanto que o segundo maior percentual de respostas (27\%) consideram os impactos ocorridos depois dos treinamentos como adequados. As respostas dos colaboradores, quando afirmam existir transformações depois dos treinamentos, estão de acordo com as respostas do Gestor de Recursos Humanos, pois todos eles responderam que existem impactos e que essas transformações causam melhorias para empresa. Isso confirma o pensamento de Abbad (2000) que diz que quando o treinamento é aplicado depois de identificado deficiências na organização, procurando resolvê-las, é possível observar a satisfação dos colaboradores, pois estes passam a compreender melhor os processos ligados à produção. O gráfico abaixo ilustra essas respostas. 
Id on Line Revista Multidisciplinar e de Psicologia

Id on Line Multidisciplinary and Psychology Journal

Gráfico 04: Avaliação dos impactos ou transformações ocorridas depois dos treinamentos.

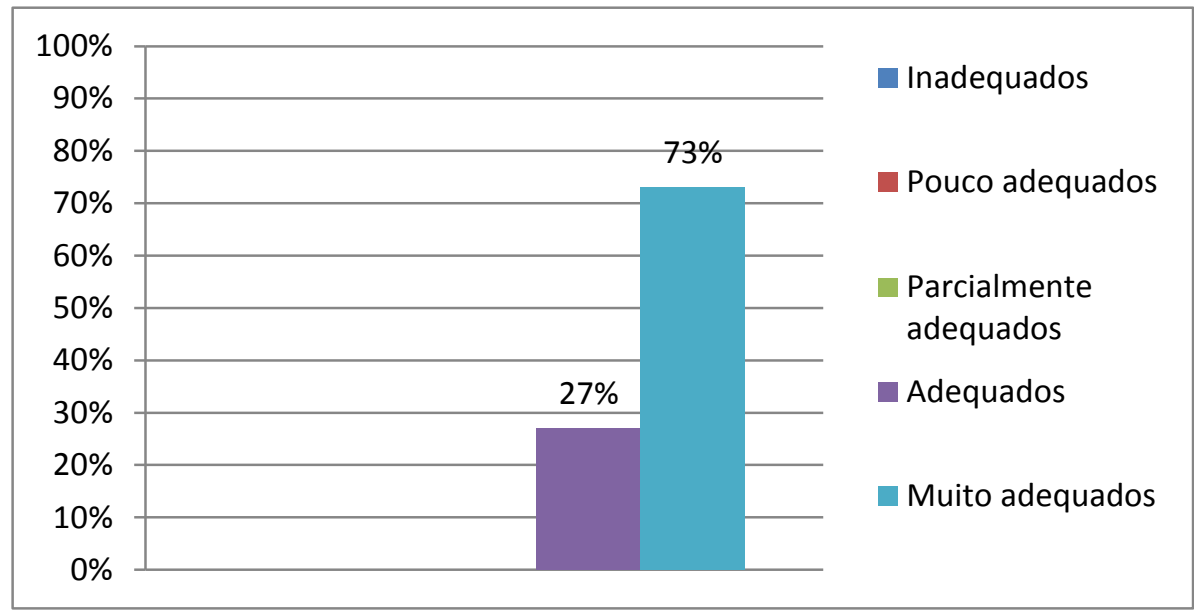

Fonte: Dados da pesquisa (2016)

Sobre qual era a opinião dos funcionários sobre as melhorias ocorridas no setor de produção após os treinamentos, observa-se que todos os colaboradores concordam que existem benefícios, ocorrem transformações positivas depois de terem participado dos programas de treinamentos existentes na empresa, sendo que existe um índice elevado de respostas que afirmam existir ótimas melhorias (70\%) no setor de produção após a aplicação dos treinamentos, enquanto que o segundo maior percentual das respostas para esta pergunta (30\%), consideram essas melhorias como boas. Compreende-se neste caso que o treinamento é capaz de provocar transformações no setor produtivo da empresa e que tanto na visão dos colaboradores quanto do gestor, o treinamento é capaz de causar melhorias significativas no setor de produção da empresa, pois todos eles estão inseridos no processo produtivo e são os agentes ativos na produção da organização.

Para Meneses (2002) a eficiência do treinamento está relacionada com a melhora significativa da organização, desde que seja implantado no programa de treinamento tudo aquilo que foi planejado para corrigir falhas, sendo possível ainda conferir resultados para observar acertos e caso erros ainda permaneçam, novos treinamentos aconteçam, com realização de feedbacks para desfrutar melhorias. $\mathrm{O}$ gráfico abaixo ilustra essas respostas. 
Id on Line Revista Multidisciplinar e de Psicologia

Id on Line Multidisciplinary and Psychology Journal

Gráfico 05: Melhorias no setor de produção após os treinamentos.

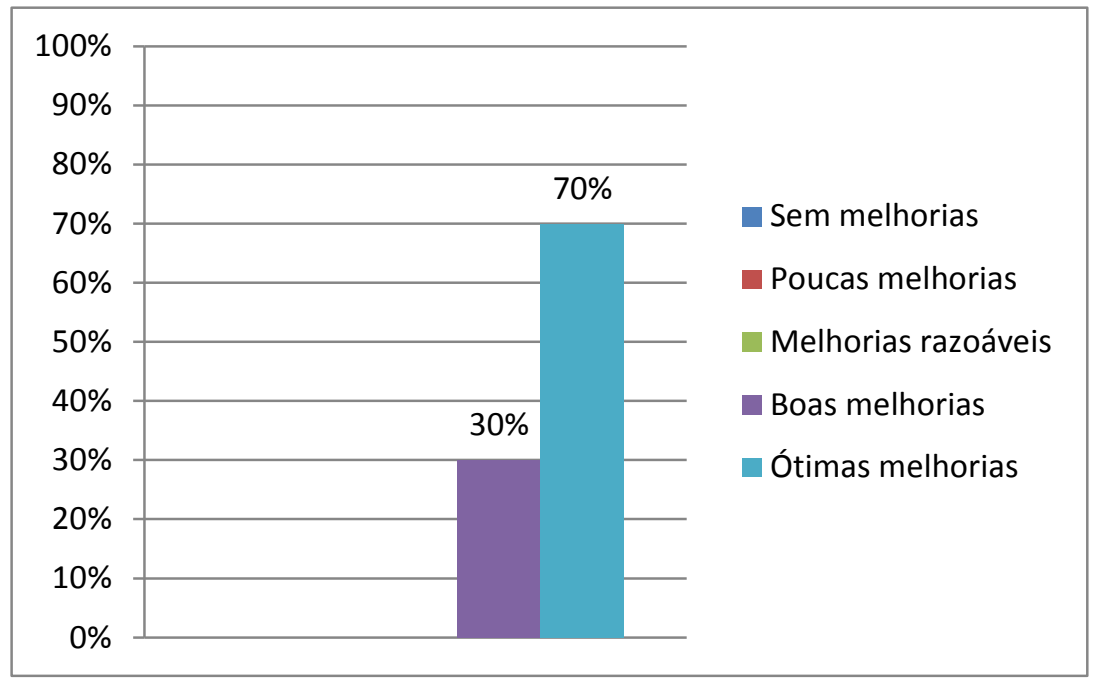

Fonte: Dados da pesquisa (2016)

Os funcionários ainda foram questionados sobre quais são os impactos observados no setor de produção após a aplicação dos treinamentos. Nesta questão, os colaboradores poderiam assinalar mais de uma opção que estavam disponíveis e ainda poderiam comentar outros impactos que não estavam nas alternativas. Todos os funcionários responderam a opção de que esses impactos estão relacionados com a diminuição de erros/falhas no processo produtivo, confirmando mais uma vez a opinião dos colaboradores com as do gestor, quando os mesmos confirmam que essas transformações estão relacionadas à diminuição de atividades falhas que prejudicam a produção da organização. A opção de aumento da qualidade dos produtos ficou em segundo lugar, com $53 \%$.

Em terceiro lugar, com 30\%, a opção de que existem impactos após a aplicação dos treinamentos no aumento da produção. Com relação ao índice máximo obtido na pesquisa relacionado à diminuição de erros/falhas no processo produtivo, esse resultado está de acordo com a concepção de Sallorenzo (2000), que diz que os treinamentos propiciam o amadurecimento dos colaboradores, pois logo estes passam a estarem mais confiantes no setor de produção da organização. Lacombe (2005) também completa dizendo que é no treinamento que as pessoas se preparam para desempenhar as suas atividades dentro da empresa. O gráfico abaixo ilustra essas respostas. 
Id on Line Revista Multidisciplinar e de Psicologia

Id on Line Multidisciplinary and Psychology Journal

Gráfico 06: Impactos observados no setor de produção após a aplicação dos treinamentos.

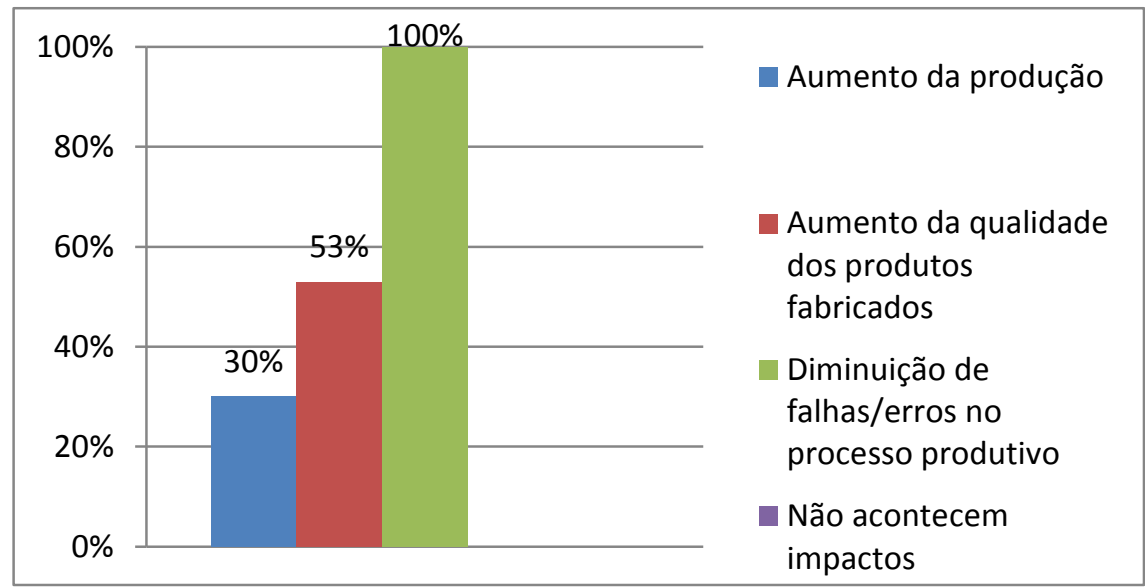

Fonte: Dados da pesquisa (2016)

É possível observar com esses resultados obtidos na pesquisa, que o treinamento é um meio pelo qual torna as pessoas aptas a desenvolverem seus papéis dentro da empresa, qualificando as mesmas e aperfeiçoando o processo produtivo da empresa. Lerner (2002) comenta que é no treinamento que as organizações encontram auxílio para melhorarem as suas atividades, qualificando os seus profissionais para desempenharem com êxito a ocupação dentro da empresa.

\section{Considerações Finais}

Os resultados da pesquisa se mostraram satisfatórios, pois o objetivo deste estudo foi alcançado, que foi de analisar os impactos que o treinamento proporciona para a empresa bem como a sua importância para melhorar os processos, destacando a sua importância e a sua função no setor de produção da empresa. Foi possível definir o treinamento, mostrando a sua importância, as fases de implantação, o planejamento, execução, avaliação e observar a eficiência quando o mesmo é aplicado corretamente, sendo possível ainda identificar as transformações ocorridas após a aplicação dos treinamentos na empresa pesquisada, pois tanto o Gestor de Recursos Humanos quanto os próprios colaboradores da empresa, relataram impactos positivos que beneficiaram o setor de produção da empresa. O treinamento de pessoal nas organizações é importante por auxiliar os empresários a atingirem seus objetivos organizacionais em um processo de melhoramento contínuo.

A pesquisa conseguiu mostrar ainda que quando o treinamento é bem planejado, existindo assim uma adequação dos seus métodos, é possível observar um alto índice de aceitação por parte dos funcionários, sendo que estes se sentem mais preparados para desempenharem suas funções dentro da empresa, diminuindo a ocorrência de erros/falhas no processo de produção, que são acompanhados por 
Id on Line Revista Multidisciplinar e de Psicologia

Id on Line Multidisciplinary and Psychology Journal

indicadores de qualidade na empresa. Verifica-se que a aplicação do treinamento é importante para o gestor e colaboradores.

É importante que pesquisas científicas estejam sempre acompanhando essas transformações causadas pelos treinamentos nas empresas, pois novos métodos estão sempre surgindo e empresas buscam inovação na forma de repassar novos conhecimentos. Acompanhar esse fenômeno é importante para o avanço do conhecimento científico na área de Recursos Humanos.

Funcionários precisam ser fortalecidos para satisfazer os clientes, melhorando a produtividade da empresa. O treinamento sendo, portanto indispensável para um desenvolvimento por excelência. Investir no trabalhador se torna uma necessidade para sua permanência no mercado e para fidelidade de seus clientes. Por esta razão as empresas devem privilegiar o investimento em recursos humanos, pois com treinamento, a empresa e os empregados estarão caminhando para o sucesso.

\section{Referências}

ABBAD, G. S. Um modelo integrado de avaliação do impacto do treinamento no trabalho Impact. Tese (doutorado) - Instituto de Psicologia, Universidade de Brasília, Brasília, 2000.

BASTOS, A. V. B.; BORGES-ANDRADE, J. Comprometimento com o Trabalho: Padrões em Diferentes Contextos Organizacionais.ERA: Revista de Administração de Empresas, v. 42, n. 2, abrjun, 2002. Disponível em: < http://rae.fgv.br/rae/vol42-num2-2002/comprometimento-com-trabalhopadroes-em-diferentes-contextos-organizacionais>. Acesso em: 01 nov. 2015.

CHIAVEnAtO, I. Gestão de Pessoas: O novo papel dos recursos humanos nas organizações. 3 ed.. Rio de Janeiro: Elsevier, 2008.

CHIAVENATO, I. Recursos Humanos. 7. ed. São Paulo: Atlas, 2002.

DUTRA, J. S. Gestão por competências: um modelo avançado para o gerenciamento de pessoas. São Paulo: Editora Gente, 2001

FRANÇA, A. C. L. Práticas de Recursos Humanos. 1. Ed. São Paulo: Atlas, 2012.

FREITAS, I. A.; BORGES-ANDRADE, J. E. Efeitos de treinamento nos desempenhos individual e organizacional. RAE: Revista de Administração de Empresas, São Paulo, v. 44, n. 3, p. 44-56, jul./set. 2004. Disponível em: <http://www16.fgv.br/rae/redirect.cfm?ID=2197>. Acesso em: 01 nov. 2015.

GIL, A. C. Gestão de pessoas: enfoque nos papéis profissionais. São Paulo: Atlas, 2001.

GIL, A. C. Como elaborar projetos de pesquisa. 4. ed. São Paulo: Atlas, 2008.

GRAMIGNA, M. R. Modelo de competências e gestão dos talentos. /Maria Rita Gramigna - 2. ed. São Paulo: Pearson Prentice Hall, 2007. 
KROEHNERT, G. Jogos para treinamento em Recursos Humanos. $1^{\text {a }}$ ed. Editora Manole Ltda. São Paulo, 2001.

LACOMBE, F. J. M. Recursos Humanos: princípios e tendências. São Paulo: Saraiva, 2005.

LACERDA, É. R. M.; ABBAD, G. Impacto do treinamento no trabalho: investigando variáveis motivacionais e organizacionais como suas preditoras. Revista de Administração Contemporânea, v. 7, n. 4, p. 77-96, dez. 2003.

LERNER, W. Competência é essencial na Administração. São Paulo: Global, 2002.

MARRAS, J. P. Administração de Recursos Humanos. 14ª Ed., São Paulo, Saraiva, 2011.

MENESES, P. P. M. Auto-eficácia, lócus de controle, suporte à transferência e impacto de treinamento no trabalho. Dissertação (mestrado) - Universidade de Brasília, Brasília, 2002.

MILIONI, B. A. Integrando o levantamento de necessidades com a avaliação e validação do treinamento. In: BOOG, G. G. Manual de treinamento e desenvolvimento ABTD: um guia de operações. São Paulo: Makron Books, p. 9-27, 2001.

SANTOS, A. M. Planejamento de Treinamento: Um Estudo de Caso na Atlas Copco/ Contrato Morro Agudo. Paracatu-MG. P. 21 - 26. 2011.

SALAS, E.; CANNON-BOWERS, J. A. The science of training: a decade of progress. Annual Review Psychology, n. 52, p. 471-499, 2001.

SNELL, S. BOHLANDER, G. Administração de Recursos Humanos. Tradução Maria Lúcia G. L. Rosa e Solange Aparecida Visconti; revisão técnica Flávio Bressan. - São Paulo: Cengage Learning, 2009.

SALLORENZO, L. H. Avaliação do impacto de treinamento no trabalho: analisando e comparando modelos de predição. Dissertação (mestrado) - Universidade de Brasília, Brasília, 2000.

VARGAS, M. R.; ABBAD, G. Bases conceituais em treinamento, desenvolvimento e educação T\&D. In: BORGES-ANDRADE, J. E.; ABBAD, G. S.; MOURÃO, L. (Org.). Treinamento, desenvolvimento e educação em organizações e trabalho: fundamentos para gestão de pessoas. Porto Alegre: Artmed. p. 137-158, 2006.

ZARIFAN, P. Objetivo Competência: por uma nova lógica. Tradução Maria Helena C. V. Trylinski. - 1. ed. - 3. Reimpr. - São Paulo: Atlas, 2008.

Como citar este artigo (Formato ABNT):

ANDRADE, W.M.A.; ALMEIDA NETO, J.L. Impactos que o Trainamento ocasiona no Setor de produção: Estudo de Caso em uma Empresa de calçados de Juazeiro do Norte - CE. Id on Line Revista Multidisciplinar e de Psicologia, Julho de 2016, vol.,10 n.30, Supl 1. p. 236-255. ISSN 1981-1179. 